\title{
FORMAÇÃO CONTINUADA E DESENVOLVIMENTO PROFISSIONAL DE PROFESSORES DE CIÊNCIAS: ANOTAÇÕES DE UM PROJETO
}

\author{
Sandra Escovedo Selles ${ }^{12}$ \\ Faculdade de Educação/Espaço UFF de Ciências, Universidade Federal Fluminense
}

\section{Resumo}

Este artigo discute algumas contribuições de um projeto de educação continuada para o desenvolvimento profissional de professores de Ciências. Partindo de uma discussão presente na literatura onde se cunhou a terminologia "formadores de formadores", analisa-se o papel multiplicador dos seus participantes, coordenando ações educativas regionais voltadas a professores de Ciências. São discutidas diferentes dimensões de desenvolvimento profissional, metodológica e institucionalmente consideradas, com especial ênfase, ao que poderia ser tomado como indicadores de desenvolvimento profissional. Sugere-se que programas de formação continuada que valorizem a participação docente e reconheçam o papel multiplicador do professor são, potencialmente, capazes de contribuir para o seu desenvolvimento profissional. $\mathrm{O}$ artigo termina por argumentar que a formação continuada de professores, como meio de alimentar o processo de desenvolvimento profissional, deve assentar-se sob uma base pedagógica, que permita a atualização e ampliação do conhecimento científico-educacional, e uma base político-profissional que inclua estratégias de reformulação $d$ as condições da profissão docente.

\section{Abstract}

This article discusses the contributions to the professional development of science teachers from an In-Service programme. An analysis of the participants' multiplying role, within a project, is made. Different dimensions of professional development are discussed. It has taken into consideration both the methodological and institutional approach and what can be considered as professional growth indicators. The results of the project have shown that its approach is potentially capable of reducing the gap between school and academic languages and also, to contribute to teacher professional development. We argue that teachers' continuing education as a means of fostering professional development, rests upon, both a pedagogical basis, and a political-professional one.

\footnotetext{
1 Professora lotada no Departamento Sociedade, Educação e Conhecimento da Faculdade de Educação da Universidade Federal Fluminense.

${ }^{2}$ Trabalho realizado com apoio da FAPERJ.
} 


\section{Introdução}

A formação de um professor é um processo contínuo. O momento de seu ingresso ao curso de formação inicial é apenas um marco numa trajetória de crescimento onde, somados aos constituintes da história de vida deste indivíduo, irão conjugar-se conhecimentos de uma dada área específica, teorias pedagógicas e elementos práticos oriundos da atividade docente e, em conjunto, formam a base sobre a qual a profissão irá se alicerçar. Diversos autores referem-se a estes elementos da ação docente como "saberes docentes" ou "saberes da profissão docente" (Tardif, Lessard \& Lahaye, 1991), "conhecimento pedagógico" (Shulman, 1987) ou mesmo "sabedoria docente" (Elliott, 1993).

Ao lado do estudo sobre a formação do professor, muito se discute sobre o que se constitui o seu desenvolvimento profissional, uma vez que é amplamente reconhecido que a formação inicial é insuficiente para proporcionar todos os elementos necessários a uma prática consistente (Shulman,1987; Pessoa de Carvalho \& Gil-Perez, 1992; Carrascosa, 1996; Furió, 1994). Há uma limitação inerente à própria natureza da formação inicial que nos leva a indagar até que ponto o recém-egresso, a despeito da qualificação outorgada pela universidade, seria, efetivamente, um professor. Considerando-se, entretanto, que as atividades docentes, como todos os processos sociais, são marcadas pela diversidade e caracterizadas por uma dinâmica não determinística, seria impossível antecipar a experiência pedagógica aos futuros professores nos cursos de licenciatura. Portanto, parece ser consensual que é imprescindível que o professor em exercício disponha de um programa de formação continuada que seja capaz de funcionar, não apenas como oportunidade de atualização de conhecimentos, face às inúmeras inovações que surgem, mas também como elemento "decodificador" das práticas vivenciadas no dia a dia da sala de aula.

Paralelamente, o desenvolvimento profissional situa-se, com explícita complexidade, para além do campo das aquisições e renovações pedagógicas. Insere-se também num contexto onde questões de ordem salarial e condições básicas da ação docente vão convergir para demandas mais claras sobre planos de carreira e status da profissão.

As múltiplas facetas da ação docente e a necessidade de sua identificação profissional num país como o nosso são críticas. Sua credibilidade é costumeiramente atacada e faz-se necessário ampliar a discussão sobre o desenvolvimento da profissão, apoiando-se em diversas fontes, sobretudo a partir de estudos teóricos fundamentados em bases empíricas.

Este trabalho toma os resultados de um projeto de educação continuada e se dispõe a discutir como pode contribuir para o desenvolvimento profissional de professores de Ciências. Cabe ressaltar que não faz uma leitura quantitativa de seus dados, mas ao invés, constrói linhas de reflexão a partir de um conjunto de eixos temáticos que emerge desta análise recorrendo, para isto, na maior parte das vezes, de referenciais teóricos disponíveis na literatura de formação de professores. Não pode ser tomado, por esta razão, como uma avaliação strictu sensu. $\mathrm{Na}$ verdade, pretendemos fazer uma leitura interna das ações do projeto, buscando construir categorias que venham contribuir para analisar alguns ângulos da formação continuada de professores. Partindo de uma discussão presente na literatura onde se cunhou a terminologia "formadores de formadores" (Gil-Pérez, 1996; Demo, 1992), analisamos o papel 
multiplicador dos participantes de um projeto de formação continuada ${ }^{3}$, ao coordenarem ações educativas regionais voltadas a professores de Ciências.

\section{Ação multiplicadora num projeto de formação continuada}

O projeto em questão encontra-se no seu sexto ano de desenvolvimento ${ }^{4}$ e é resultante de uma iniciativa da universidade no sentido de promover um maior intercâmbio com as escolas. Participaram dele professores do Ensino Fundamental da rede pública de seis regiões do Rio de Janeiro, discutindo subsídios teorico-metodológicos que contribuiriam para a melhoria da prática docente. Embora o projeto se ocupe de questões relativas à sala de aula, sua ação instrumentalizadora também abrange outras dimensões do ensino de Ciências. Ao valorizar a ação docente, dirige-se igualmente a setores hierárquicos superiores, como a direção da escola, as secretarias de educação locais e demais estruturas associadas, focalizando assim, questões mais abrangentes.

A metodologia de trabalho compreende encontros nas diversas regiões, cuja programação inclui debate teórico em grupos e oficinas pedagógicas. Na estratégia metodológica, dois aspectos se destacam. O primeiro deles é a participação de professores representantes destas regiões que acumulam o papel de organizadores do evento e multiplicadores das idéias do projeto. Esta função multiplicadora tem se mostrado fundamental na construção de uma referência mediadora entre as escolas e a universidade. O segundo é a opção pela realização dos encontros nas escolas. Questões relativas à problemática vivenciada pelos professores são examinadas no próprio locus da prática docente.

Desde o início do projeto houve um acompanhamento de suas atividades e para todas elas os professores expressaram, por escrito, sua opinião. O planejamento dos encontros é feito de forma dinâmica, utilizando inclusive, este repertório de críticas e sugestões feitas. A avaliação, ao mesmo tempo em que serve como norteadora das ações futuras, oferece uma medida do desempenho do projeto. Desta avaliação, por exemplo, podemos dimensionar até que ponto a estratégia metodológica contempla a necessidade do professor. É, neste sentido, que a opção de ir à escola é traduzida na linguagem docente como "ir ao professor" e isto é particularmente apontado nas avaliações dos professores como algo bem recebido. Igualmente, a avaliação parece indicar que os debates e oficinas têm favorecido uma circulação de idéias novas entre os participantes.

Outro aspecto que se destaca é que muitos ministrantes das oficinas são professores da rede pública que, aprofundando seu envolvimento no projeto, passam a freqüentar a universidade e outros círculos de renovação acadêmica e encorajam-se a apresentar suas experiências pedagógicas a seus colegas. Por outro lado, é preciso destacar que o projeto conta com apoio institucional da universidade e de uma agência financiadora ${ }^{5}$ que subsidia os

\footnotetext{
${ }^{3}$ O projeto, Uma Andorinha Só Não Faz Verão, é desenvolvido pelo Espaço UFF de Ciências, da Universidade Federal Fluminense. Atualmente, este projeto encontra-se em uma nova etapa e focaliza o trabalho docente de professores em uma escola estadual no município de Niterói, RJ. Os dados trazidos à análise neste texto, referem-se ao período compreendido entre 1995 a 1999.

${ }^{4}$ Desde 1995 cerca de 1265 professores participaram das atividades do projeto.

${ }^{5}$ FAPERJ (Fundação de Apoio à Pesquisa no Estado do Rio de Janeiro)
} 
professores coordenadores das regiões. Este fator parece conferir uma maior credibilidade ao empreendimento, ao mesmo tempo em que introduz um tratamento profissional a uma atividade desenvolvida por uma categoria profissional, acostumada a engajar-se em trabalhos voluntários.

Existem dois princípios sobre os quais se alicerça esta proposta de formação continuada de professores. O primeiro deles considera que uma abordagem que vise aumentar a autoestima do professor e ajudá-lo a (re-)descobrir sua competência profissional, precisa reconhecer que este aprendizado constrói-se numa via de "mão dupla". Ou seja, não apenas o conhecimento acadêmico produzido na universidade tem a contribuir aos professores, como, igualmente, a vivência oriunda do trabalho diário na escola fornece importante contribuição a ser explorada teoricamente. Proporciona-se um intercâmbio em que os parceiros deste empreendimento precisam refletir sobre seus diferentes saberes. Neste sentido, surgem variadas oportunidades de interlocução que são particularmente enriquecedoras para todos os envolvidos, independente de qual instância educacional atuem. Esta complementaridade é apontada por Tardif, Lessard \& Lahaye (1991: 317) quando afirmam que "os processos de produção dos saberes sociais e os processos sociais de formação podem ser considerados como dois fenômenos complementares no quadro da cultura moderna e contemporânea". A estratégia de concentrar todas as atividades nas escolas, ao invés de realizá-las nos ambientes da universidade, sugere uma reafirmação deste princípio.

As atividades desenvolvidas nos encontros consistiam em eleger problemas reais vivenciados pelos professores na sua rotina didática e levá-los a uma ampla discussão. O início do debate partia de um professor universitário que se incumbia de iniciar a discussão, na perspectiva de quem compartilhava seus saberes e não comparecia ali para 'ensinar' a um grupo que 'nada sabia'. Eram organizados trabalhos de grupo para a discussão inicial, embasada em algum texto acadêmico. A discussão final era então conduzida por alguns professores membros da equipe.

O segundo princípio norteador do projeto centra-se no reconhecimento de que, para o envolvimento do professor em propostas de formação continuada, há necessidade de considerar o seu papel multiplicador. Esta ação multiplicadora tem sido estudada ao longo do desenvolvimento do projeto e parece compreender duas categorias de professores: aqueles que se incorporam ao projeto como participantes (os que afluem aos encontros) e aqueles para os quais são delegadas tarefas específicas na escola-pólo de uma região. Estes últimos funcionam como elos entre escola e universidade, permitindo que o fluxo de informações transite nas duas direções.

A ação multiplicadora pode ter desdobramentos variados e em alguns casos, seu acompanhamento é difícil de ser feito. Foi possível construir uma melhor compreensão do papel multiplicador a partir dos professores que estabeleceram um vínculo com o projeto, particularmente, daqueles que possuíam responsabilidades em tarefas específicas. Por ação multiplicadora estamos chamando todo esforço desenvolvido pelos professores para ampliar, em diversos ambientes educacionais, as possibilidades de sua atividade docente. Ainda que este conceito tenha, no contexto deste trabalho, uma aferição qualitativa, é possível demarcar algumas destas ações: i) estender a participação dentro da escola para além do cumprimento restrito de ministrar aulas, propondo, por exemplo, leituras, grupos de estudos, organizar clubes 
de ciências, debates dentro da escola. ${ }^{6}$ etc.; ii) trazer outros professores para os encontros; iii) atuar em outros espaços e projetos educacionais, como, participação em outros grupos de estudo); iv) organizar e oferecer novas oficinas nos encontros a partir de sua experiência docente.; v) ocupar posições estratégicas dentro do sistema de ensino (como por exemplo, acumular a função de coordenador da área na escola, ser responsável por pólos de ciências etc.); vi) ampliar sua atuação profissional, integrar equipe de organizadores de exposição científica em espaços não-formais de educação etc.

Esta é uma relação de atividades desenvolvidas pelos professores envolvidos no projeto que podem caracterizar este papel multiplicador referido anteriormente. É importante ressaltar que o objetivo deste trabalho não se coloca numa abordagem quantitativa destes indicadores e assim não dispomos de dados numéricos que nos permitam caracterizar quantos professores desenvolveram esta ou aquela ação. É ainda necessário destacar que um mesmo professor atua simultaneamente em diversas das atividades enumeradas, muitas vezes, em diferentes projetos. Dentro desta perspectiva, não é possível caracterizar de forma objetiva, por exemplo, o quanto um professor melhorou sua relação com seus alunos ou algo semelhante.

Por outro lado, consideramos que capturar quantitativamente o quanto avançou esta relação seria creditar unicamente ao projeto a transformação. Sabemos que, na verdade, 0 engajamento ao projeto pode desencadear um processo de mudanças, entretanto, apreciar os seus desdobramentos em bases de uma relação causal simples, seria extremamente limitante. Inúmeros fatores de ordem pessoal, existencial, institucional, econômica, política etc. conjugamse na transformação de um professor. Pretendemos, assim, creditar ao projeto, um potencial transformador que vai ao encontro da competência docente ajudando-o a percebê-la, uma vez que ela é desconhecida ou desprezada pelo próprio professor. Em outras palavras, para promover uma mudança, a ação do projeto deve ser efetiva suficiente e encontrar ressonância no desejo do professor, mas deve estar conjugada a outros fatores extrínsecos que viabilizem sua consecução, o que é, em suma, contribuir para que o professor reconheça sua competência profissional.

\section{Analisando possibilidades de desenvolvimento profissional de professores de Ciências}

Dentre os resultados alcançados pelo projeto, até o momento, passamos a considerar em que medida possibilitam, ainda que, potencialmente, um ganho profissional para os professores participantes. A partir da ação multiplicadora do projeto, é importante caracterizar a dinâmica interna e suas interações e quais viabilizariam o desenvolvimento profissional docente. Podemos assim considerar quais estratégias empregadas pelo projeto foram bem sucedidas e, em que medida, seriam capazes de promover o desenvolvimento profissional. A interação dos professores com o projeto gera um comportamento diferenciado que os leva buscar novas alternativas para sua prática e o projeto passa a ter um papel aglutinador na promoção de crescimento. No trabalho de avaliação de uma das etapas do projeto, Pietzsch

\footnotetext{
${ }^{6}$ Por exemplo, um dos professores multiplicadores iniciou um grupo de estudos para desenvolver propostas de educação ambiental dentro de sua escola.
} 
(1998) analisa depoimentos escritos de professores participantes e parte deste material servenos para construir algumas categorias analíticas nas reflexões que ora fazemos.

Ainda que nossos esforços teóricos pretendam desenrolar as teias de desenvolvimento profissional, é preciso considerar que a atividade profissional insere-se nos domínios de um saber plural e seu estatuto assenta-se em bases não determinísticas. É importante que nossas tentativas de capturar a dinâmica de desenvolvimento profissional a partir de iniciativas de formação continuada, persigam elementos mais objetivos. Entretanto, consideramos que, na tentativa de quantificação desta ação, há um risco de aprisionamento do potencial transformador. Primeiro, porque poderíamos estar submetendo esta dinâmica a princípios de uma racionalidade que é absolutamente ineficiente para tratar as questões docentes. Segundo, como conseqüência deste princípio, poderíamos estar produzindo um conjunto normativo para o desenvolvimento profissional o que, em última instância, seria uma leitura empobrecedora do seu sentido. Santaella (1998: 262) discute que o contexto do desenvolvimento profissional supera a simples idéia de aperfeiçoamento que parece se justapor à formação inicial. Para esta autora, "desenvolvimento profissional é um processo que se produz ao logo de toda vida e que não está limitado a certas idades, sendo ao contrário, um processo pessoal e único pois os indivíduos são sujeitos que constroem e organizam ativamente suas próprias histórias pessoais". Desta forma, o desenvolvimento profissional não surge simplesmente como resultado de diferentes eventos na vida do professor, mas representa "um processo dialético entre os múltiplos fatores ambientais e a construção pessoal que os sujeitos fazem destes fatores" (Santaella ,1998: 262).

É possível identificar, no âmbito de ação do projeto, algumas dimensões de desenvolvimento profissional que se apresentam com uma abrangência dual: a dimensão metodológica e a dimensão institucional. A primeira delas diz respeito à opção metodológica e compreende estratégias para atualização de novas idéias científico-educacionais e o uso de uma linguagem de comunicação acessível ao professor. A segunda, refere-se aos avanços institucionais obtidos, tais como o estabelecimento de uma parceria entre a universidade e as escolas participantes e a emergência de um espaço para o debate de questões educacionais atuais, atendendo às demandas da profissão docente. Conjugadas, estas dimensões parecem convergir para alguns indicadores de desenvolvimento profissional que é representado, no contexto desta análise, pelo retorno do professor ao ambiente acadêmico e seus desdobramentos. Passaremos assim a comentar cada uma delas, considerando em que medida podem acenar para o desenvolvimento profissional dos docentes. 


\section{Dimensões de desenvolvimento profissional}

\section{A dimensão metodológica}

a) Atualização de novas idéias educacionais

Inegavelmente, o professor, como todo profissional, precisa estar atualizado para atuar na escola de seu tempo. Isto implica, não apenas na atualização dos conteúdos específicos, mas igualmente nas questões educacionais mais amplas. No caso particular do conhecimento científico, verificamos que este atinge níveis de transformação espantosos, dada a rapidez com que as informações são produzidas em todas as partes do mundo. Já se afirma correntemente que nunca a Ciência produziu tanto em tão pouco tempo. Por outro lado, as inovações científicas não surgem desconectadas de suas implicações econômico-político-sociais. Basta para isso considerar o debate amplamente veiculado pela mídia no que diz respeito ao caso da clonagem da ovelha Dolly e, mais recentemente, ao impacto da comercialização de plantas transgênicas e aos resultados do projeto genoma. Para enfrentar os questionamentos de ordem ética, moral, religiosa, etc. que a introdução destas temáticas no universo escolar implicam, fazse necessário um professor atualizado e informado sobre as diversas dimensões que uma análise mais apropriada do conteúdo exige (Leal \& Selles, 1999).

No que tange às temáticas educacionais contemporâneas, é preciso oferecer oportunidades para que o professor maneje as novas informações de forma crítica. A este respeito, Nascimento (1997: 87) afirma: ... as estratégias de formação continuada não podem objetivar apenas competência técnica, mas também o auto-conhecimento, a autonomia e o compromisso político do educador, aspectos fundamentais de sua formação profissional." Para isto, um trabalho cuidadoso de análise dos seus pressupostos teóricos torna-se imprescindível, em caráter permanente.

Tomemos o caso do construtivismo. Indevidamente, foi proposto aos professores nos últimos anos por muitas secretarias de educação de diversas regiões brasileiras, sem que lhes fossem dados elementos teóricos para sua compreensão e conseqüente "aplicação". Aquilo que deveria ser considerado uma perspectiva para a educação foi tomado como "metodologia" e o que é pior ainda, antagônica ao que foi chamado de "tradicional". Para muitos professores, construtivismo adquiriu um status de vilão educacional, desestabilizador da ordem. Ocorre que, aqueles que não conseguiam caracterizar apropriadamente sua prática docente e, pela absoluta falta de informação disponível, passaram a considerar toda sua experiência como inadequada a uma "prática construtivista" que, a seu turno, desconheciam. Assim, classificavam sua experiência anterior inadvertidamente de "tradicional", conferindo-lhe um tratamento pejorativo. Consideravam-na assim oposta ao que era proposto burocraticamente, ainda que isto representasse desprezar toda uma bagagem profissional acumulada ao longo dos anos (muitas vezes, bem sucedida).

Construtivismo e outros temas como "promoção automática", "análise de livros didáticos" e PCNs, passaram a integrar a agenda dos encontros onde os professores podiam discutir estas temáticas com seus pares. Esta estratégia, que focaliza problemas genuínos da prática docente, encontra apoio nas idéias de Gil-Pérez (1996:77) quando este autor afirma que: “... a estratégia de formação continuada potencialmente mais produtiva consiste inserir os 
professores na pesquisa dos problemas de ensino-aprendizagem de Ciências em que se baseia sua atividade docente".

Trazer estas discussões para o âmbito de um projeto de formação continuada pareceunos, não apenas necessário, como também indispensável para o desenvolvimento profissional dos seus participantes. A necessidade de esclarecer estas dúvidas e permitir acesso a referências teóricas consistentes, era assim prioritário e constou da programação dos primeiros encontros regionais. Além das discussões propostas em que textos teóricos eram trazidos à exame, os professores recebiam informações a respeito de outros eventos e aqueles que manifestavam maior interesse de aprofundar seu conhecimento sobre os temas discutidos, recebiam textos suplementares, via correspondência.

É impossível afirmar positivamente o quanto estas informações e a oportunidade de discutir um tema do cotidiano da ação docente, tenham efetivamente respondido todas as dúvidas dos professores. Creditar ao projeto uma ação redentora em relação à imposição autoritária dos órgãos normativos, não era o propósito. Deste modo, as estratégias utilizadas não foram encaminhadas comprometidas como "defesa" das idéias. Visavam propiciar um debate acadêmico para ampliar as possibilidades de compreender as questões, para além da injunção burocratizada a que tinham sido submetidos. O sentido pedagógico das determinações institucionais se perdem quando são confundidos com os processos burocratizados, sobretudo porque alija os professores e considera-os sujeitos passivos das inovações educativas. Acreditamos que o debate e o acesso à informação carregam potencial transformador que esvazia a retórica institucionalizada.

b) Uso de uma linguagem de comunicação acessível ao professor

Em muitos empreendimentos pedagógicos, uma crítica se faz constante: a comunicação entre acadêmicos e professores obstaculiza um diálogo que deveria, ao revés, fomentar o desenvolvimento profissional docente. Já há muito tempo, a distância produzida pelo discurso acadêmico tem sido considerada um fator dificultante para o engajamento do professor em mudanças de sua prática docente. Nos anos 60, Lawrence Stenhouse, propunha, na Inglaterra, um projeto de reformulação curricular, que tomava como ponto de partida a crítica dirigida à ineficiência das propostas governamentais de comunicar-se apropriadamente aos professores, por estarem impregnadas de um discurso acadêmico distante do seu contexto (Stenhouse, 1975). A solução apresentada por Stenhouse apontava para uma redefinição do papel dos professores nestas propostas, passando de meros "cumpridores" a "participantes ativos". Esta iniciativa resultou no movimento cuja denominação, "Teachers as Researchers Movement" movimento dos professores investigadores (Elliott, 1993), foi cunhada pelo próprio Stenhouse.

Dentro desta perspectiva, comunicar-se com o professor utilizando-se de uma linguagem que contivesse elementos factíveis de serem entendidos sem implicar num empobrecimento, foi tomado pelo projeto como um desafio. Seria preciso encontrar uma linguagem mediadora que não reduzisse seu entendimento e não deformasse seu sentido, para garantir o crescimento do professor, no re-exame de sua prática. Pareceu-nos oportuno optar por uma estratégia composta, onde eram oferecidos aos professores, na programação, atividades de cunho teórico (inclusive com leitura de textos) e de cunho prático onde os discursos se revezavam. 
Nesta perspectiva, os professores tiveram oportunidade de, em atividades de grupo, ler e discutir textos educacionais, produzir pequenos textos, comunicá-los oralmente à totalidade dos participantes e participar da discussão com representantes da comunidade acadêmica. Para muitos, aquela era uma primeira oportunidade após muitos anos de afastamento das discussões educacionais. Outros, reconheciam que tinham priorizado, em oportunidades de formação continuada anteriores, experiências práticas (do tipo oficinas temáticas), por não se sentirem à vontade com o discurso acadêmico.

A dimensão institucional

\section{Estabelecimento de parcerias: universidade e escolas participantes}

A literatura, tanto nacional quanto internacional, que trata da formação continuada de professores é pródiga em apontar entraves institucionais para a participação docente (Nascimento, 1997, Marandino, 1997, Krasilchik, 1987). Por exemplo, Marandino (1997:170) lista alguns desses impedimentos que variam desde a inexistência de uma estrutura escolar que cuide dos alunos (substituindo o professor) enquanto o professor é liberado para participar, quanto à precariedade institucional de oferecer meios à participação docente (por exemplo, a Secretaria de Educação "não libera o ponto" do professor). Navegar pelas vias burocráticas, parece ter se tornado, para muitas iniciativas de formação profissional docente, um desafio onde cautela, ousadia e profissionalismo precisam combinar-se adequadamente.

A longevidade do projeto, seu aspecto sazonal e as relações institucionais estabelecidas nestes anos permitiram construir elos de ligação entre a universidade e as escolas, na tentativa de minimizar muitos dos obstáculos referidos anteriormente. Este processo é resultante do esforço conjunto que supera entraves burocráticos, reafirma um compromisso em bases profissionais e tem como resultado a credibilidade dos propósitos. Como conseqüência, os parceiros institucionais deste empreendimento posicionaram-se, em bases de reciprocidade, no reconhecimento dos seus papéis. Cada um deles elevou seus padrões de desempenho para produzir as atividades e atender, da melhor maneira possível, as demandas dos participantes.

Neste sentido, ao longo dos anos do projeto, as escolas têm providenciado as condições físicas e infra-estrutura de apoio para os encontros (mesmo arcando com inúmeras dificuldades, sobretudo as de ordem financeira), envolvendo toda a equipe da escola e até mesmo alunos, que se ocupam de diversas atividades-chave. Em um nível hierárquico mais elevado, o projeto também alcançou credibilidade junto às Secretarias de Educação onde, principalmente, no âmbito municipal, há a participação efetiva das CRE (Coordenadoria Regional de Educação, no município do Rio de Janeiro), seja na divulgação, como também liberando os professores de suas aulas nas ocasiões necessárias. Sem dúvida, o trabalho dos professores teve no suporte institucional advindos da universidade e da FAPERJ, grandes aliados no estabelecimento das parcerias. Outro fator importante foi a decisão da Secretaria de Educação do Município do Rio de Janeiro de instituir os pólos de Ciências e Matemática, que permitiram, assim, que o projeto concentrasse sua área de ação na região coberta pelo Pólo e realizasse ações complementares.

\section{Indicadores de desenvolvimento profissional}


Krasilchik (1987), num dos seus trabalhos mais referenciados, enumera algumas condições que favorecem o êxito de iniciativas de formação continuada de professores, dentre as quais destacamos: a participação voluntária, a existência de material de apoio, a coerência e a integração conteúdo-metodologia, participação de grupos de professores de uma mesma escola etc.

Ainda que não venhamos a discutir cada uma destas condições, parece-nos que elas se organizam em torno de um núcleo comum, qual seja: qualquer programa que pretenda investir na melhoria da ação docente precisa tomar as necessidades do professor como o elemento basilar para o planejamento de suas atividades. Muitos são os argumentos falaciosos de que 0 professor não consegue definir suas necessidades ou até que tenha dificuldade de elencar suas preferências. Demo (1992:36) ao afirmar que "nossas crianças, como nossos professores sabem muito pouco" expõe uma triste face das limitações dos nossos professores, não por sua incapacidade intelectiva, mas pelo descaso institucional que prefere oferecer-lhes soluções paliativas para suprir o arremedo de uma formação ineficiente.

Todos estes elementos são reflexos de uma tradição de desmoralização de uma profissão que, em nosso país, luta por conquistar seu espaço profissional. Solomon (1998:137) muito claramente se expressa a este respeito:

"Os professores constituem-se o patrimônio cultural mais importante na educação de um país, e o principal patrimônio destes professores não é o domínio de conteúdos específicos ou pedagógicos per ser, embora isto seja fundamental. Estou convencida de que esta entidade oculta é o status dos professores, tanto aos olhos da comunidade como aos seus próprios olhos. Se o panorama educacional de um país chega a um ponto no qual os professores são considerados como pessoas que não conseguiram tornar-se intelectuais universitários, ou, pior ainda, que os professores consideram suas próprias carreiras como tal, então a educação nesse país enfrenta graves problemas! "

Desta forma, qualquer programa de formação continuada que menospreze as demandas docentes (seja este menosprezo mascarado por formulações pseudo-teorizantes desvinculadas de um trabalho investigativo sério e, portanto, desprovido de uma tomada sistemática das necessidades docentes, ou não), está condenado a ser mero elemento decorativo, assentado nas estantes dos inúmeros insucessos que acumulamos ao longo dos anos.

No projeto que ora analisamos, sabedores dos imensos obstáculos históricoinstitucionais, algumas precauções foram tomadas. Ainda que o projeto não se defina como "periferia-centro"7, pretendeu-se incorporar princípios democráticos que encorajassem os professores a buscar fontes acadêmicas para alimentar seus anseios profissionais. Reconhecemos, neste processo, dois fatores que podem ser tomados como indicadores de desenvolvimento profissional e que passaremos a discutir.

\footnotetext{
${ }^{7} \mathrm{Na}$ literatura, este termo se refere a modelos curriculares de inspiração democrática. O “centro" corresponde a uma equipe de educadores encarregados, essencialmente, de disseminar as propostas construídas e desenvolvidas pela "periferia", ou seja, professores e coordenadores das escolas participantes de algum projeto de reformulação curricular. Em um trabalho anterior (Selles, 1994), discutimos este modelo.
} 


\section{Retorno dos professores ao ambiente acadêmico}

Estrategicamente, todo o esforço de atualização e engajamento dos professores com vistas a uma ampliação de suas possibilidades profissionais fez-se, inicialmente, a partir de sua participação no projeto. Seu envolvimento nas discussões, sua percepção da coerência das informações, bem como o reconhecimento da validade prática dos subsídios propostos nas oficinas temáticas, terminaram por fazê-lo reconhecer sua própria competência, aumentar sua auto-estima e desejar estender suas perspectivas profissionais. É preciso destacar que sugerimos que estes fatores decorrem de uma iniciativa do projeto, mas dependem do desejo do professor e é isto que o conduz de volta aos ambientes universitários para o prosseguimento de sua formação docente.

Inúmeros têm sido os casos de participantes deste projeto que retornaram à universidade ingressando em programas de pós-graduação (lato sensu e strictu sensu). Muito comum também foi o engajamento em projetos de formação continuada voltados a professores de Ciências ${ }^{8}$. Esta ação multiplicadora tem encorajado muitos professores a assumirem o papel de dinamizadores de oficinas e apresentarem suas experiências docentes como subsídios aos seus colegas. Passam assim a integrar a programação de cursos e oficinas de formação continuada nos diversos municípios envolvidos pelo projeto. No caso específico do município do Rio de Janeiro, onde existem Escolas-Pólo de Ciências e Matemática, um número substantivo de responsáveis nomeados pela Secretaria Municipal de Educação do Rio de Janeiro para estas escolas são alunos ou egressos da Pós-Graduação Lato Sensu em Ensino de Ciências da UFF ${ }^{9}$.e mantém vínculos com o projeto.

O estabelecimento de inúmeras iniciativas de formação no Grande Rio, favorece um entrelaçamento institucional com a participação destes professores. Esta ação conjunta tem características de uma "rede de formação continuada" onde emerge o papel do que é chamado pela literatura de "formadores de formadores" (Gil-Pérez,1996; Demo, 1992) o que, em suma, ilustra a ação multiplicadora a que nos referimos. Vale destacar a existência do Grupo de Ação Coordenada, iniciativa coordenada pelo Centro de Ciências do Estado do Rio de Janeiro (CECIERJ) que reúne diversos projetos de Educação em Ciências, promovendo reuniões regulares, divulgando suas atividades e organizando eventos anuais, nos quais, os participantes do projeto que ora analisamos têm atuado freqüentemente. Inseridos neste contexto, os professores ampliam sua atuação profissional e oferecem sua contribuição a partir do próprio processo de crescimento que estão vivenciando.

Este fato, apesar de muitas vezes passar desapercebido (e quiçá, negligenciado em muitos estudos) merece uma cuidadosa atenção. Imaginemos, talvez com algum esforço, o que significa para um professor que enfrenta a dura rotina docente em um grande centro urbano, redescobrir-se capaz de ampliar seus horizontes profissionais. A recente publicação de Codo (1999) apresenta-nos uma extensa coleção dos relatos das frustrações e angústias dos

\footnotetext{
${ }^{8}$ No Espaço UFF de Ciências, contamos com a colaboração de um grande número de professores participantes do projeto. Da mesma forma, incluem-se muitos colaboradores de outras instituições, como o Projeto Fundão da UFRJ, por exemplo.

${ }^{9}$ Vide relação fornecida pela Secretaria Municipal de Educação do Rio de Janeiro por ocasião do I Seminário de Ensino de Ciências da Rede Municipal do Rio de Janeiro.
} 
profissionais docentes, muitos deles vítimas da "síndrome do burnout"10. Um programa de formação continuada, ainda que imerso nas inúmeras complexidades conjunturais precisa acenar com possibilidades de resignificação da ação docente apostando no aumento da autoestima do professor.

Ë possível, por exemplo, tomar como indicador de desenvolvimento profissional a participação de muitos professores do projeto em congressos científicos. Participar de reuniões de alto nível acadêmico tem um efeito altamente revitalizador para o professor pois permite que ele revisite sua prática e incorpore reflexões teóricas recolhidas nestes eventos. Diversos professores tiveram, assim, oportunidades de sistematizar experiências pedagógicas, numa interface estabelecida com um projeto de pesquisa ${ }^{11}$ que resultou na produção de material instrucional utilizado e avaliado nas oficinas do projeto. Este material passou a integrar o acervo didático da universidade e tornado disponível para empréstimo. Desta experiência, alguns trabalhos acadêmicos foram apresentados em congressos científico-educacionais pelos próprios professores.

Nesta dinâmica de transformação profissional os professores foram capazes de socializar os próprios benefícios de sua volta ao ambiente universitário e enriquecer sua prática a partir de um movimento reflexivo desencadeado ao longo de sua participação no projeto. Mais do que isso, resgataram a consciência de sua competência. Estes resultados são concordantes com as idéias de Nascimento (1997) e Carrascosa (1996) referidos anteriormente e representam aumento da competência técnica, auto-conhecimento e autonomia. Considerar estes fatores como indicadores de desenvolvimento profissional parece oportuno, embora reconheçamos que isto demanda um outro estudo para melhor aprofundar o que sugerimos neste texto.

\section{Participação do professores nos espaços de debate das questões científico-educacionais atuais}

O professor demanda espaços de discussão de sua prática, ainda que não consiga muitas vezes bem caracterizá-la, já que, a profissão docente é tida como aquela incapaz de zelar pela sua memória (Shulman, 1987). Carecem, assim, registros destas práticas, espaços para reflexão e, como decorrência, um empobrecimento de sua identidade profissional. A existência de um espaço para debate das questões pertinentes à prática educativa, tem sido referida por alguns autores como essencial para o desenvolvimento de uma atitude reflexiva que propulsione o crescimento profissional Schön (1983).

O projeto teve intenção explícita de construir um espaço de reflexão sobre as práticas docentes e, efetivamente, passou a ser referido como tal. Tomamos como base para esta

10 “ uma síndrome através da qual o trabalhador perde o sentido da sua relação com o trabalho, de forma que as coisas já não o importam mais e qualquer esforço lhe parece inútil. Esta síndrome afeta, principalmente, profissionais de área de serviços quando em contato direto com seus usuários. Como clientela de risco são apontados os profissionais de educação e saúde, policiais e agentes penitenciários, entre outros. Schaufeli et al. (1994) chegam a afirmar que este é o principal problema dos profissionais de educação” (Codo, 1999: 238)

${ }^{11} \mathrm{O}$ projeto 'O professor e a dinâmica docente”, financiado pela FINEP. 
afirmativa os registros das avaliações realizadas ao longo destes anos, bem como as sucessivas solicitações de inclusão de mais regiões para a realização dos eventos (inicialmente eram apenas três regiões) e o número crescente de seus participantes. (Pietzsch, 1998).

$\mathrm{Na}$ construção deste espaço cabe destacar o papel dos professores multiplicadores, atuando como mediadores da linguagem de comunicação e ouvintes das necessidades dos docentes. "Professores que falam para outros professores" parecem ter um poder de persuasão consideravelmente maior do que simplesmente ser convidado à discussão por professores universitários. Parece que os professores sentem-se mais ameaçados pelos representantes acadêmicos e também tendem a considerar que o discurso dos professores multiplicadores está mais perto daquilo que consideram pertencer ao seu "mundo escolar real".

Por participar mutuamente da condição de atores da ação docente e serem capazes de refletirem sobre esta ação, reúnem condições que contribuem para o desenvolvimento profissional de seus pares. Por outro lado, o processo tem contornos de reciprocidade e o seu próprio desenvolvimento profissional surge, como conseqüência.

\section{Considerações finais}

As reflexões sobre o que consideramos resultar da ação formadora de um projeto endereçado a professores de Ciências em serviço, indicam-nos que o processo de desenvolvimento profissional docente pode avançar a partir do envolvimento do professor em programas similares. É bem verdade que este texto não tem a pretensão de explorar profusamente a questão, mas modestamente, acredita que foi capaz de enumerar fatores de desenvolvimento profissional e escrutinar algumas de suas relações com os programas de formação continuada. Existem, ainda, muitos outros ângulos a serem discutidos quando desejamos analisar esta problemática numa perspectiva mais ampla e que precisarão ser endereçados em trabalhos futuros.

Podemos dizer, entretanto, que a formação continuada de professores de Ciências e conseqüente enriquecimento de sua ação docente desloca-se a partir de duas necessidades básicas: num pólo encontra-se a necessidade de atualizar e ampliar os conhecimentos científicos, num mundo em constante e rápida transformação científico-tecnológica; em outro, situa-se a necessidade de informação e envolvimento na discussão sobre as questões educacionais, uma vez que não é possível conceber um ensino de Ciências isolado do contexto educacional. Complementam estes dois eixos, um conjunto de subsídios teorico-metodológicos capazes de auxiliar a ação do professor na sala de aula e dentro da escola, na execução de trabalhos com seus parceiros institucionais. Este conjunto de componentes, que deve fazer parte da agenda mínima de programas de formação continuada, representa o que chamamos a base pedagógica do desenvolvimento profissional docente. É impossível tentar avançar na direção de uma plenitude na profissão sem que o professor esteja de posse deste instrumental básico para seu exercício diário. Reconhecer que o desenvolvimento profissional docente é um processo continuado, recorrente e inacabado, requer ações de efeito imediato e outras de longo prazo.

Entretanto, se por um lado esta base pedagógica não pode prescindir de renovação e reflexão constantes, seria ingênuo considerar que por si mesma seria capaz de fazer o 
professor avançar em sua carreira, sem uma revisão mais ampla das condições da profissão e, mais do que isto, do reconhecimento do conceito social que recebe. Os debates sobre o profissionalismo docente (como qualquer outra profissão) requerem uma cuidadosa discussão sobre seu papel social, sobre regulamentações e condições para o seu exercício. No caso particular de nosso país, que carece de uma tradição sólida de bases profissionalizantes para 0 magistério, estes fatores encontram-se complexamente imbricados em políticas educacionais que não conseguiram, até o presente, definir-se em favor de ideais democráticos. Como conseqüência, os rumos destas políticas não apenas contribuíram para o declínio vertiginoso do status social da profissão, como também não conseguiram incluir na pauta das discussões um tratamento mais sério em relação à natureza do saber-fazer docente.

Assim, promover o desenvolvimento profissional, tomado como base de uma ação transformadora da qualidade do ensino, implica não apenas atender às demandas pedagógicas dos professores, mas, igualmente, estabelecer uma estratégia revolucionária que reformule as condições da profissão docente e devolva a dignidade a seu trabalhadores. Isto constituiria a base político-profissional do trabalho docente.

Neste trabalho, ocupamo-nos em discutir as demandas pedagógicas sem desconsiderar que elas podem resultar em tentativas frustadas quando não forem consideras no conjunto da natureza da profissão docente. Os resultados deste projeto demonstraram, entretanto, que sua abordagem é potencialmente capaz de reduzir a distância entre o discurso acadêmico e 0 escolar e contribuir para o desenvolvimento profissional dos professores.

Agradecimentos: Gostaria de agradecer às professoras Glória Queiróz e Ana Cléa Ayres, pela discussão da primeira versão deste artigo. Sou também muito grata às professoras Lori Pietszch, Maria Ferreira, Fátima Castanho Miranda e Cristina Ribeiro Cohen, por compartilharem um aprendizado sobre a profissão docente, bem como pelas muitas oportunidades de examinar o desenvolvimento deste projeto e que foram de grande importância para elaboração deste texto.

\section{Referências}

Carrascosa, J. (1996). Análise da formação continuada e permanente de professores de Ciências Ibero-americanos. In: Menezes, L.C. (org.). Formação continuada de professores de Ciências - no âmbito ïbero-americano. (1996). Campinas: Ed. Associados.

Codo, W. (coord.) (1999). Educação: carinho e trabalho. Petrópolis: Vozes.

Demo, P. (1992). Formação de formadores básicos. Em Aberto, ano 12 (54), Abr./Jun.

Elliott, J. (1993) Action-research for Educational Change. Mylton Keynes, Open University Press.

Furió Mas, C.J. (1994) Tendencias actuales en la formación del profesorado de Ciencias. Enseñanza de las Ciencias, 12(2), pp.188-199. 
Gil-Pérez, D. (1996) Orientações didáticas a formação continuada de professores de Ciências. In: Menezes, L.C. (org.). Formação continuada de professores de Ciências - no âmbito ïberoamericano. (1996). Campinas: Ed. Associados.

Krasilchik, M. (1987). O professor e o currículo de Ciências. São Paulo: EPU.

Leal, M.C. e Selles, S.E. (1999). Dolly na escola. Pátio - Revista Pedagógica. Ano 3, número 11 , pp.52-55.

Marandino, M. (1997). A formação continuada de professores em ensino de ciências: problemática, desafios e estratégias. In: Candau, V.M. Magistério - Construção Cotidiana. Petrópolis: Vozes.

Nascimento, M.G. (1997). A formação continuada dos professores: modelos, dimensões e problemática. In: Candau, V.M. Magistério - Construção Cotidiana. Petrópolis: Vozes.

Pessoa de Carvalho, A.M e Gil-Pérez, D. (1992). Formação de Professores de Ciências. São Paulo, Cortez.

Pietszch, L. L.(1998). Uma Andorinha Só Não Faz Verão: Análise Preliminar de um Projeto de Educação Continuada para Professores de Ciências. Monografia. São Paulo. Universidade Federal Fluminense. (Monografia, Graduação).

Santaella, M.C. (1998). Formación para la professión docente. Madri: Grupo FORCE/Grupo Editora Universitaria.

Schön, D. (1983). The Reflective Practicioner. London, Jossey-Bass.

Shulman, L. (1987). Knowledge and Teaching: Foundations of the New Reform. Havard Educational Review, v. 57 (1), pp. 1-22.

Solomon, J. (1998). Desenvolvimento profissional de professores: prática evolucionária, reforma curricular e mudança cultural. Educar em Revista, número 14pp. 137-150. Curitiba: Editora UFPR

Stenhouse, L. (1975). An introduction to curriculum research and development. London, Heinemann.

Tardif, M., Lessard, C. e Lehaye, L. (1991). Os professores face ao saber Esboço de uma problemática do saber docente. Teoria e Educação, no 4 pp. 215-234. 